\title{
Testing the Impact of Counseling over Time on Non-Urgent Undergraduate Life Satisfaction
}

\author{
Gary Blau ${ }^{1}$, John DiMino ${ }^{2}$, Iris Abreu ${ }^{2} \&$ Kayla LeLeux-LaBarge ${ }^{2}$ \\ ${ }^{1}$ Human Resource Management Department, Fox School of Business, Temple University, Philadelphia, USA \\ ${ }^{2}$ Tuttleman Counseling Services, Temple University, Philadelphia, USA \\ Correspondence: Gary Blau, Human Resource Management Department, Temple University, 349 Alter Hall, \\ 1810 Liacouras Walk, Philadelphia, PA, 19122, USA. E-mail: gblau@temple.edu
}

Received: May 25, 2017

doi:10.5539/jedp.v7n2p59
Accepted: June 8, 2017

Online Published: July 4, 2017

URL: http://doi.org/10.5539/jedp.v7n2p59

\begin{abstract}
Data for non-urgent undergraduate clients at a University Counseling Center (UCC) were collected using on-line surveys over three time-periods. Despite the expected diminishing number of participants over time, within-time correlations generally showed that level of mental distress and mental health concerns were negatively related to life satisfaction, while self-esteem was positively related. Using a smaller sample of matched-over-three time-periods clients, levels of mental distress and mental health concerns significantly declined, while life satisfaction significantly increased. The strongest changes for this complete data sample were found from Time 1 to Time 3 for reduced mental health concerns and increased life satisfaction. These findings reinforce that additional counseling sessions for undergraduates may be beneficial, and that spreading these sessions out may also be useful. Scientifically demonstrating to higher-level University administration that a UCC can help undergraduates in distress should ideally help the UCC to increase its allocation of university-based resources.
\end{abstract}

Keywords: life satisfaction, mental health concerns, impact of counseling, non-urgent undergraduates

\section{Introduction}

Choosing to seek counseling at a University Counseling Center (UCC) is an important decision in the lives of many undergraduates. The thought of sharing one's personal history and experiences to a stranger can be very scary (Rosenbaum \& Liebert, 2015). Unfortunately, mental health issues continue to grow on college campuses, and there seems to be no abatement to the increased use of UCCs. Looking at data across 275 University Counseling Centers (Gallagher, 2014), 94\% of UCC directors reported greater overall numbers of students seeking services, with 52\% of UCC clients having severe psychological problems (up from $44 \%$ in 2013 ). The purpose of this study is to examine the impact of counseling services on life satisfaction and related correlates over time on a sample of undergraduates. These are important issues to consider as UCCs compete for university resources with other campus stakeholders (Hunt, Watkins, \& Eisenberg, 2012).

\subsection{Prior General Research on Undergraduate Life Satisfaction and Several Correlates}

Life satisfaction among college students is a key component of subjective well-being (Diener, Suh, Lucas, \& Smith, 1999). It is defined as an individual's evaluation of the quality of one's life against self-imposed standards (Diener, Emmons, Larsen, \& Griffin, 1985). Recent studies have shown that life satisfaction is a protective factor against a non-suicidal self-injury in college students (Kress, Newgent, Whitlock, \& Mease, 2015), and that life satisfaction mediates the relationships of attachment anxiety and avoidance to two domains of graduation-related concerns for college seniors: career-related and change and loss-related (Lane, 2016). Prior research has shown that self-esteem was positively correlated to life satisfaction, while neuroticism was inversely related to life satisfaction (Pavot \& Diener, 1993). Diener and Seligman (2002) found that the happiest group of undergraduate students scored lower on several psychopathology scales (e.g., depression, psychopathic, family conflict) of the Minnesota Multiphasic Personality Inventory compared to less happy groups. Happiness was based on aggregated peer reports of affect balance, and self-reports of life satisfaction and affect balance collected over two months. This suggests that mental health concerns are negatively related to life satisfaction. 
Using data from the National Comorbidity Survey Replication, Kessler et al. (2005) estimated that three-quarters of lifetime mental disorders (e.g., anxiety, mood, impulse and impulse control) have their first onset by the traditional college age range of 18-24. Using various pre-counseling and post-counseling measures, Brunner, Wallace, Reymann, Sellers and McCabe (2014, p. 264) called today's college students the "most stressed" generation of college students. When simultaneously comparing in-counseling versus not-in-counseling undergraduate samples, researchers have reported that students who are in-counseling have significantly lower academic adjustment, social adjustment and personal emotional adjustment (DeStefano, Mellott, \& Petersen, 2001), and lower perceived well-being and mental health (Green, Lowry, \& Kopta, 2003). This research collectively suggests that level of mental distress, mental health concerns and self-esteem are correlates of life satisfaction, and college students are an important sample to study.

\subsection{Brief Nature of College Counseling}

Given the increased demand of services on many university campuses (Gallagher, 2014), counseling with college students is typically of short duration. Using the data gathered from 1,698 college student clients across 42 universities, Draper, Jennings, Baron, Ozgur and Shankar (2002) found that the average number of sessions per client was 3.3. In another review, Ghetie (2007, p. 51) noted a median (midpoint of a frequency distribution) of 4-5 counseling sessions and a mode (most frequent number) between 1 and 2 sessions. Mahon et al. (2015) found that $37 / 124(30 \%)$ of undergraduate clients completed a minimum of three counseling sessions, with the remaining 87 either never returning for a second session or dropping out after two sessions. While it can be very challenging to build a longer-term sample of undergraduates receiving counseling services, prior research suggests that even a short-term intervention can increase important undergraduate outcomes. Mahon et al. (2015) found a significant decrease in counselor-reported client symptom severity. Blau et al. (2016) found that the means of social connectedness and life satisfaction significantly increased over time for 28 undergraduates, with a median of four counseling sessions (after initial triage assessment). The current study measured a different set of antecedent variables, i.e., mental distress, mental health concerns, and self-esteem, as well as life satisfaction, and collected a longer-term sample of students in counseling (up to a median of 10 weeks, range of eight to 12 weeks), while testing two hypotheses. For the hypotheses below (H1 and H2), life satisfaction was defined as an individual's evaluation of the quality of one's life (Diener et al., 1985) and three different time periods were used to define "over time":

H1-level of mental distress and mental health concerns will be negatively related, while self-esteem will be positively related, to life satisfaction.

H2-over time counseling will reduce the level of mental distress and mental health concerns and increase self-esteem and life satisfaction.

\section{Method}

\subsection{Samples and Procedures}

Three undergraduate samples based on time length in counseling were collected in this study. All data were voluntarily collected at the main campus of a large state-supported urban university's UCC in the Mid-Atlantic region of the United States. The first sample is labeled as initial counseling session sample or Time 1. Both subsequent samples were derived from this initial sample and are labeled Time 2 and Time 3. However, for any given client, the nature of their mental issue, as well as client/therapist availability did not allow for a standardized number of sessions or time periods to represent when clients filled out the Time 2 or Time 3 surveys. Given this non-standardized time-period and number of counseling sessions provided for participants before taking Time 2 and Time 3 surveys, a range of sessions and time-periods were used (reported below).

Data were collected for 261 undergraduates who registered for counseling services at the UCC between the fall of 2013 to the fall of 2016. Institutional Review Board (IRB) approval was given for all data collection, and data were collected using online surveys which went directly into Qualtrics' data bases. Lucas (2012) used a similar three-year period (2004 to 2007) to collect an undergraduate counseling sample. These undergraduate students had been designated at their initial counseling session (i.e., an in-person triage interview), as non-urgent (non-suicidal or risk to self/others) by the triage therapist. Students were asked if they wished to voluntarily participate in a research study looking at the impact of counseling on student outcomes. The Time 1 clients took their survey after triage but before beginning counseling (i.e., intake). The time span between triage and intake could be anywhere from that day to over two to three weeks, depending on current client demand for services and therapist availability. Sample demographics for the Time 1 sample are reported below. 
Undergraduate clients who filled out the initial survey (Time 1) were given the option of listing the last four digits of their nine-digit university identity number so that their responses, while receiving counseling, could be tracked over time but their individual identities would remain protected. Clients could take the Time 1 survey either at the UCC's self-help center or at home using a survey link. Using their email addresses recorded at triage, clients were contacted for Time 2 collection at four weeks from their triage appointment date and again for Time 3 at eight weeks from date of triage appointment. A general email was sent out to all post triage clients on a rolling weekly basis during a semester. As a check, clients were asked what survey they were filling out (Time 1, Time 2, Time 3).

Of the 261 participants from Time 1, N =70/261 (27\%) filled out a second survey at Time 2. This Time 2 sample reported a median of three counseling sessions after intake (range 1 to 8 ) over a period of six weeks (range 4 to 10 weeks). Of the Time 1 clients, $\mathrm{N}=35 / 261$ (13\%) filled out the third survey or Time 3. This Time 3 sample reported a median of six counseling sessions after intake (range less than 5 to 12) over a period of ten weeks (range 8 to 12 weeks). Thus there is a client participation rate decline from $\mathrm{N}=261$ (Time 1) to $\mathrm{N}=70$ (Time 2) to $\mathrm{N}=35$ (Time 3). In order to improve the longitudinal response rate, a $\$ 50$. random-drawing lottery for matched ID repeat-respondents was approved by the IRB part-way through the data collection process. However, this incentive had little impact in improving the matched respondent participation rate. This response-rate percentage decline is consistent with prior research (Lucas, 2012). In addition, archival data from the UCC study site showed that over the last three years, by 4 sessions (full intake plus three sessions after) over $60 \%$ of the non-urgent clients had stopped counseling. Across all three time periods there were only 20 clients who matched across time, when using their four-digit identification number. Despite assurances of confidentiality, clients may not have wanted their answers tracked longitudinally. This three-time match sample $(\mathrm{N}=20)$ will be called the complete sample.

\subsection{Measures}

Respondent demographics. Demographics were collected only at Time 1. Data collected were: main mental health issue for presenting to counseling, gender, ethnic background, status entering university, current residential status, parents' highest education level, self-reported Grade Point Average (GPA), age, referral source for counseling, days waited for intake (after triage) and status as a full-time student (defined as taking over 12 credits/semester).

Level of mental distress, mental health concerns, self-esteem, and life satisfaction. These variables were measured at all three times. Level of mental distress was measured by asking clients to "rate your current level of mental distress that brought you to counseling". An eight-point Likert response scale was used, where: $1=$ none, $2=$ very little, $3=$ a little, $4=$ moderate, $5=$ a lot, $6=$ severe, $7=$ very severe, $8=$ unbearable. Mental health concerns were measured using six items. Items were "I have recently: (1) lost a lot of sleep over worrying, (2) felt constantly under some type of strain, (3) felt that I could not overcome my difficulties, (4) been feeling unhappy or depressed, (5) been losing confidence in myself and (6) been thinking of myself as a worthless person". These six items represent the Symptoms of Mental Disorder factor in the short-form of the General Health Questionnaire (Hu, Stewart-Brown, Twigg, \& Weich, 2007). The 4-point response scale used by Hu et al. (2007, p. 1006) was expanded to a 7-point response scale to keep response scale consistency. The higher the total score the greater one's mental health concerns, with a Cronbach's alpha of . 80 for the Time 1 sample. Self-esteem was measured using five items. Items were: (1) "I feel like I am a person of worth, at least on an equal basis with others"; (2) "I feel like I have a number of good qualities"; (3) "I am able to do things as well as most people"; (4) "I take a positive attitude towards myself"; and (5) "on the whole I am satisfied with myself". These are the positively worded items from the Rosenberg (1965) 10-item General Self-Esteem Scale. The other five reverse scored items from this scale were not used because research has shown that the negative items constitute a separate factor (Greenberger, Chen, Dmitrieva, \& Farruggia, 2003). The higher the score the greater one's self-esteem, with a Cronbach's alpha of .92 for the Time 1 sample. Life Satisfaction was measured by using three items (Pavot \& Diener, 1993). Items were: (1) "I am satisfied with my life", (2) "In most ways my life is close to ideal", and (3) "The conditions of my life are excellent". Data analyses across multiple samples has shown that these three items (of the five-item total) have the strongest item factor loadings and item-total correlations (Pavot $\&$ Diener, 1993). The higher the total score the greater one's life satisfaction, with a Cronbach's alpha of .86 for the Time 1 sample. 


\subsection{Data Analyses}

The first hypothesis (H1) was tested using correlation analyses on the four variables, i.e., level of mental distress, mental health concerns, self-esteem and life satisfaction, within each time-period for all complete data samples. The second hypothesis (H2) was tested using the General Linear Model (GLM) for each of the four variables. The GLM was appropriate for a repeated measures design (Stevens, 1996). There was no homogeneity of variance test with the GLM because only one group, i.e., the complete sample, was used. However, Mauchly's sphericity test, which is appropriate for 3 or more levels of a repeated measure factor (i.e., time), was calculated prior to testing between group differences (Stevens, 1996). A non-significant test indicated that the variances of the differences between all possible pairs of within-subject conditions (i.e., levels of independent variable or 3 different times) was equal and the subsequent multivariate F test was not inflated. For each GLM test, Mauchly's sphericity test was not significant, supporting the subsequent multivariate $F$ test reported. If a significant multivariate $\mathrm{F}$ was found, the least squares difference post hoc test between groups was then used (Stevens, 1996). Since direction was specified in H2, an a priori one-tail test is justified (Stevens, 1996). Effect size for the largest significant difference between groups within a variable was also reported (Cohen, 1988).

\section{Results}

\subsection{Demographic Comparison of Complete to Initial Sample}

Table 1 shows a demographic comparison of the complete sample $(\mathrm{N}=20)$ to the initial Time 1 sample $(\mathrm{N}=$ 261). Overall, there was general consistency between the two samples, suggesting that the subsequent missing data after the Time 1 sample was not due to any demographic variable measured, such as ethnicity, gender, or age (Roth, 1994). Comparing both samples to more general prior research: anxiety and depression were the top two mental health concerns of undergraduate clients (Barr, Krylowicz, Reetz, Mistler, \& Rando, 2011), and males were generally less likely to seek counseling than females (Nam et al., 2010). Over a two-year period at a large urban community mental health center in the northwestern United States, Sparks, Daniels and Johnson (2003) found higher percentages of white (versus non-white) and self-referral (versus other referral) participants.

Table 1. Demographic variables for three-time complete versus initial samples

\begin{tabular}{|c|c|c|}
\hline Variable & Complete $(\mathrm{N}=20)$ & Initial $(\mathrm{N}=261)$ \\
\hline \multicolumn{3}{|l|}{ Main Mental Health Issue } \\
\hline Anxiety & $45 \%$ & $42 \%$ \\
\hline Depression & $30 \%$ & $28 \%$ \\
\hline \multicolumn{3}{|l|}{ Gender } \\
\hline Male & $15 \%$ & $25 \%$ \\
\hline Female & $80 \%$ & $73 \%$ \\
\hline Transgender & $5 \%$ & $2 \%$ \\
\hline \multicolumn{3}{|l|}{ Ethnic background } \\
\hline Non-white & $30 \%$ & $26 \%$ \\
\hline White & $70 \%$ & $74 \%$ \\
\hline \multicolumn{3}{|l|}{ Status } \\
\hline No transfer & $65 \%$ & $69 \%$ \\
\hline Transfer & $35 \%$ & $31 \%$ \\
\hline \multicolumn{3}{|l|}{ Residential status } \\
\hline Non-commuter & $70 \%$ & $76 \%$ \\
\hline Commuter & $30 \%$ & $24 \%$ \\
\hline \multicolumn{3}{|l|}{ Parents' education } \\
\hline Less than 4-year college degree & $25 \%$ & $34 \%$ \\
\hline At least 4-year college degree & $75 \%$ & $66 \%$ \\
\hline Self-reported GPA & 3.3 & 3.2 \\
\hline
\end{tabular}




\begin{tabular}{lll}
\hline Age, M (range) & $21(18-29)$ & $20(18-30)$ \\
& & \\
Referral Source & $60 \%$ & $59 \%$ \\
Self & $40 \%$ & $41 \%$ \\
Other (e.g., family, friend) & 17 & 15 \\
Mean Days Waited for Intake & $95 \%$ & $96 \%$ \\
\hline
\end{tabular}

\subsection{Testing the Two Hypotheses}

To test H1, i.e., level of mental distress and mental health concerns will be negatively related, while self-esteem will be positively related, to life satisfaction, Pearson correlational analyses were used. Within-time correlations for each complete sample data set are shown in Table 2.

Table 2. Means, standard deviations, and correlations among level of mental distress, mental health concerns, self esteem and life satisfaction within three separate times

\begin{tabular}{|c|c|c|c|c|c|c|}
\hline \multicolumn{7}{|l|}{ Time $1(N=164)$} \\
\hline$\underline{\text { Variable }}$ & $\mathrm{M}$ & $\mathrm{SD}$ & 1 & 2 & 3 & 4 \\
\hline 1. Level of Mental Distress ${ }^{a}$ & 4.93 & 1.07 & --- & & & \\
\hline 2. Mental Health Concerns ${ }^{\mathrm{b}}$ & 5.21 & 1.06 & $.47^{* *}$ & & & \\
\hline 3. Self-Esteem ${ }^{\mathrm{b}}$ & 4.58 & 1.44 & $-.36 * *$ & $-.50 * *$ & & \\
\hline 4. Life Satisfaction ${ }^{\mathrm{b}}$ & 3.76 & 1.52 & $-.43 * *$ & $-.48 * *$ & $.68 * *$ & --- \\
\hline \multicolumn{7}{|l|}{ Time $2(\mathrm{~N}=53)$} \\
\hline$\underline{\text { Variable }}$ & M & $\mathrm{SD}$ & 1 & 2 & 3 & 4 \\
\hline 1. Level of Mental Distress ${ }^{a}$ & 4.21 & 1.35 & ----- & & & \\
\hline 2. Mental Health Concerns ${ }^{b}$ & 4.72 & 1.29 & $.60 * *$ & & & \\
\hline 3. Self-Esteem ${ }^{\mathrm{b}}$ & 4.76 & 1.61 & $-.45^{* *}$ & $-.64 * *$ & & \\
\hline 4. Life Satisfaction ${ }^{\mathrm{b}}$ & 4.21 & 1.51 & $-.54 * *$ & $-.60 * *$ & $.75 * *$ & --- \\
\hline \multicolumn{7}{|l|}{ Time $3(\mathrm{~N}=35)$} \\
\hline$\underline{\text { Variable }}$ & M & $\mathrm{SD}$ & 1 & 2 & 3 & 4 \\
\hline 1. Level of Mental Distress ${ }^{a}$ & 3.83 & 1.42 & ----- & & & \\
\hline 2. Mental Health Concerns ${ }^{\mathrm{b}}$ & 4.10 & 1.31 & $.60 * *$ & & & \\
\hline 3. Self-Esteem ${ }^{\mathrm{b}}$ & 5.28 & 1.33 & -.28 & $-.58 * *$ & & \\
\hline 4. Life Satisfaction ${ }^{\mathrm{b}}$ & 4.71 & 1.29 & $-.40 *$ & $-.63 * *$ & $.62 * *$ & ---- \\
\hline
\end{tabular}

Note. $* \mathrm{p}<.05 ; * * \mathrm{p}<.01$ (two-tailed). Listwise deletion of data within each time.

${ }^{\mathrm{a}}$ Level of Mental Distress, $1=$ none, $2=$ very little, $3=$ a little, $4=$ moderate, $5=$ a lot, $6=$ severe, $7=$ very severe, $8=$ unbearable.

${ }^{\mathrm{b}}$ Mental Health Concerns, Self-Esteem, Life Satisfaction, $1=$ strongly disagree, $2=$ disagree, $3=$ somewhat disagree, $4=$ neither agree nor disagree, $5=$ somewhat agree, $6=$ agree, $7=$ strongly agree.

Using listwise deletion reduced the sample sizes from Time $1(\mathrm{~N}=164)$ to Time $2(\mathrm{~N}=53)$ and Time $3(\mathrm{~N}=35)$. Despite the decrease in sample sizes over time, the results were generally consistent across each sample. Level of mental distress and mental health concerns exhibited a significant negative correlation to life satisfaction, while self-esteem showed a positive relationship to life satisfaction. In addition, the absolute value of the correlations 
between level of mental distress, mental health concerns and self-esteem were .75 or less, indicating that these measures were distinct (Stevens, 1996). Overall, these results supported H1.

To test H2, i.e., over time counseling will reduce the level of mental distress and mental health concerns and increase self-esteem and life satisfaction, the GLM procedure was used. The results are shown in Table 3. Significant overall changes (multivariate $\mathrm{F}$ ) in the complete sample were found for three of the four variables tested: level of mental distress $(p<.05)$; mental health concerns $(p<.01)$, and life satisfaction $(p<.05)$. Level of mental distress declined, and the mean difference decline between Time 1 (4.58) to Time 3 (3.58) was significant. A large effect size of .79 (Cohen, 1988) was found for this decline. Mental health concerns also declined, and the mean difference declines between Time 1 (5.05) and Time 2 (4.65) to Time 3 (3.94) were significant. For the largest difference in groups, the effect size was .93 (Cohen, 1988), which is classified as large. Life satisfaction increased and the differences between Time 1 (3.80) and Time 2 (4.15) to Time 3 (4.82) were significant. A large effect size of .70 was found between the biggest difference groups. The multivariate $\mathrm{F}$ for self-esteem was not significant $(\mathrm{F}=2.36)$. Although the descriptive data show smaller cell mean changes over time, self-esteem did increase. Overall, there was partial support for $\mathrm{H} 2$.

Table 3. General linear model testing significance of outcome variable, post hoc differences within subgroups, and largest effect size for complete sample

\begin{tabular}{|c|c|c|c|c|c|c|c|c|c|c|c|c|}
\hline Outcome Variable & \multicolumn{3}{|c|}{ Level of Mental Distress } & \multicolumn{3}{|c|}{ Mental Health Concerns } & \multicolumn{3}{|c|}{ Self-Esteem } & \multicolumn{3}{|c|}{ Life Satisfaction } \\
\hline Multivariate $\mathrm{F}$ & \multicolumn{3}{|c|}{$\mathrm{F}=2.74 *$} & \multicolumn{3}{|c|}{$\mathrm{F}=5.70 * *$} & \multicolumn{3}{|c|}{$F=2.36$} & \multicolumn{3}{|c|}{$\mathrm{F}=4.58^{*}$} \\
\hline \multirow[t]{2}{*}{ Cell Means } & $\mathrm{T} 1$ & $\mathrm{~T} 2$ & $\mathrm{~T} 3$ & $\mathrm{~T} 1$ & $\mathrm{~T} 2$ & T3 & $\mathrm{T} 1$ & $\mathrm{~T} 2$ & T3 & $\mathrm{T} 1$ & $\mathrm{~T} 2$ & T3 \\
\hline & $4.58^{\mathrm{a}}$ & 4.05 & $3.58^{\mathrm{b}}$ & $5.05^{\mathrm{a}}$ & $4.65^{\mathrm{a}}$ & $3.94^{\mathrm{b}}$ & 4.56 & 4.79 & 5.30 & $3.80^{\mathrm{a}}$ & $4.15^{\mathrm{a}}$ & $4.82^{\mathrm{b}}$ \\
\hline Effect Size $^{\mathrm{d}}$ & \multicolumn{3}{|c|}{$d=.79$} & \multicolumn{3}{|c|}{$d=.93$} & & & & \multicolumn{3}{|c|}{$d=.70$} \\
\hline
\end{tabular}

Note. $\mathrm{N}=20 ; \mathrm{T} 1=$ Time $1 ; \mathrm{T} 2=$ Time $2 ; \mathrm{T} 3=$ Time 3.

Response scale for all outcome variables, $1=$ strongly disagree to $7=$ strongly agree

${ }^{a, b}$ Within each variable, cell means that do not share the same superscript are significantly different at the 0.05 level by the Least Significant Difference post hoc test.

${ }^{\mathrm{d} C}$ Cohen's (1988) effect size, where $d=\mathrm{M}$ (NIC)-M (ICS)/ $/$ pooled SD for largest significant difference within outcome variable groups.

$* \mathrm{p}<.05 ; * * \mathrm{p}<.01$ (both one-tailed).

\section{Discussion}

The research design of this study is rare in finding significant correlations among study variables over three time periods for an undergraduate sample of students receiving counseling services; as well as significant changes, with large effect sizes (Cohen, 1988), in three of four variables for the complete counseling sample. These results are consistent with a general Consumer Reports article on the benefits of psychotherapy (Seligman, 1995). The robustness of the findings, despite the loss in client participation over time, is encouraging. As level of mental distress and mental health concerns significantly decreased for clients, their life satisfaction significantly increased. These results are consistent with Lucas (2012) who found significant improvement in the "highly distressed" undergraduate client sub-sample between intake and their eighth session. Prior research (Kitzrow, 2009) has also shown that college students with higher perceived psychological distress were less likely to persist towards graduation, and depression was a significant predictor of both lower GPA and higher probability of dropping out (Eisenberg, Golberstein, \& Hunt, 2009). The three scales used, mental health concerns, self-esteem, and life satisfaction, were shortened versions of longer scales. However, these shortened versions each demonstrated good scale reliability. Prior research working with college student samples suggests that shorter survey length can help with a higher response rate (Fan \& Yan, 2010).

\subsection{Study Limitations}

Perhaps the biggest limitation of the current study is the loss in client sample size, especially from Time 1 ( $\mathrm{N}=$ 261) to Time $2(\mathrm{~N}=70)$, but then also to Time $3(\mathrm{~N}=35)$. Although such client loss is consistent with prior research (e.g., Draper et al., 2002; Ghetie, 2007; Lucas, 2012; Mahon et al., 2015), it is none-the-less discouraging. Natural client attrition due to treatment, i.e., clients sufficiently resolving their mental health issue 
in a short time period, played a large role in these sample size decreases over time. The loss in sample size influenced the non-significant finding for self-esteem, which still did increase over time. One contributing factor for the loss between Time 1 (after triage but before intake) to Time 2 (median of three sessions after intake) may have been the wait time for intake (Lucas, 2012) which averaged over two weeks. Millennial college students have been stereotyped as "typically impatient, want-it-now" (Rickes, 2009). Prior research has shown that as wait time increased between triage and intake, clients were less likely to show up for the scheduled intake (DiMino \& Blau, 2012).

In addition, when matching four-digit ID numbers, the complete data samples size over time periods was further reduced. Another contributing factor to difficulty in building a longitudinal sample is the "episodic" nature of counseling for many college students, which has been characterized as students seeking psychotherapy for a particular issue but then stepping away and taking a break from it, and returning later if needed (Webb \& Widseth, 1988). This episodic nature is reflected in the uneven number of counseling sessions and time period ranges after Time 1 for Time 2 and Time 3. We do know that the Time 2 sample had a median of three counseling sessions after intake, while the Time 3 sample had a median of six counseling sessions. Unfortunately, no persistence/retention data were collected. Collecting such data may be important going forward. Prior research has shown that student satisfaction with their university was positively related to undergraduate retention (Schreiner \& Nelson, 2013). It would be interesting to see if undergraduate life satisfaction also influences their retention. The final limitation was that only non-urgent clients were sampled.

\subsection{Implications for Practicing College Clinicians and Resourcing UCCs}

Scientifically demonstrating to higher-level University administration that a UCC can help undergraduates in distress should ideally help the UCC to increase its allocation of university-based resources (Bishop, 2010; Hunt et al., 2012). Linking student services to student life satisfaction can be important for improving the overall financial health of an institution. The current longitudinal findings about the positive impact of UCC services is an important part of that conversation. Such research efforts need to be continued as UCCs compete with other university stakeholders for resources (Castonguay, Locke, \& Hayes, 2011). Aggregating common data across UCCs is one way to combat limited-sample-size at a particular UCC. Kopta et al. (2014) used a data set of 13,803 clients on the Behavioral Health Measure-20 (BMH-20) across 23 UCCs in the United States from 2006-11 to show that client treatment benefit on the BMH-20 peaked between 7 to 10 sessions.

In order to "hold" non-urgent triaged clients to increase their show-rates for their intake session, experimenting with such strategies, as a self-help center and group counseling may be helpful. Follow-up with no-shows to find out why they did not come to intake (DiMino \& Blau, 2012) may also be helpful (e.g., used other coping resources, problem resolved, gave up waiting).

With regard to the study findings, the strongest change for the complete sample was found from Time 1 to Time 3 for reduced level of mental distress and mental health concerns, and increased life satisfaction.

The Time 2 sample reported a median of three counseling sessions after intake (range 1 to 8 ) over a period of six weeks (range 4 to 10 weeks), while the Time 3 sample reported a median of six counseling sessions after intake (range less than 5 to 12) over a period of ten weeks (range 8 to 12 weeks). This reinforces that additional counseling sessions for undergraduates may be beneficial (Lucas, 2012). In addition, spreading the sessions out may also be helpful. Surette and Shier (2017) recently found that while of number of sessions $($ Mean $=7)$ for their sample had a negative impact on somatization, depression and anxiety, having the sessions spread over a longer time period ( $M=18$ weeks) had a positive impact. Such research supports having the resources available in a UCC to avoid "time limited" treatment (Ghetie, 2007). Although many college students seem to successfully engage in short-term treatment (Mahon et al., 2015), knowing that additional sessions can lead to further benefits in terms of reduced mental health concerns and increased life satisfaction justifies a UCC having the resources in place, such as adequate staffing, to avoid an arbitrarily small number of sessions with college students (Lucas, 2012).

\section{References}

Barr, V., Krylowicz, B., Reetz, D., Mistler, B. J., \& Rando, R. (2011). The Association for University and College Counseling Center Directors annual survey. Retrieved from http://files.cmcglobal.com/aucccd_directors_survey_monograph_2011.pdf

Bishop, J. (2010). The counseling center: An undervalued resource in recruitment, retention and risk management. Journal of College Student Psychotherapy, 24, 248-260. https://doi.org/10.1080/87568225.2010.509219 
Blau, G., DiMino, J., DeMaria, P. A. Jr., Beverly, C., Chessler, M., \& Drennan, R. Jr. (2016). Social connectedness and life satisfaction: Comparing mean levels for two undergraduate samples and testing for improvement based on brief counseling. Journal of American College Health, 64(8), 585-592. https://doi.org/10.1080/07448481.2016.1207645

Brunner, J. L., Wallace, D. L., Reymann, L. S., Sellers, J.-J., \& McCabe, A. G. (2014). College counseling today: Contemporary students and how counseling centers meet their needs. Journal of College Student Psychotherapy, 28, 257-324. https://doi.org/10.1080/87568225.2014.948770

Castonguay, L., Locke, B., \& Hayes, J. (2011). The Center for Collegiate Mental Health: An example of a practice-research network in university counseling centers. Journal of College Student Psychotherapy, 25(2), 105-119. https://doi.org/10.1080/87568225.2011.556929

Cohen, J. (1988). Statistical Power Analysis for the Behavioral Sciences (2nd ed.). Hillsdale, NJ: Lawrence Earlbaum Associates.

DeStefano, T. J., Mellott, R. N., \& Petersen, J. D. (2001). A preliminary assessment of the impact of counseling on student adjustment to college. Journal of College Counseling, 4(2), 113-121. https://doi.org/10.1002/j.2161-1882.2001.tb00191.x

Diener, E., \& Seligman, M. E. P. (2002). Very happy people. Psychological Science, 31, 81-84. https://doi.org/10.1111/1467-9280.00415

Diener, E., Emmons, R. A., Larsen, R. J., \& Griffin, S. (1985). The satisfaction with life scale. Journal of Personality Assessment, 49, 71-75. https://doi.org/10.1207/s15327752jpa4901_13

Diener, E., Suh, E. M., Lucas, R. E., \& Smith, H. L. (1999). Subjective well-being: Three decades of progress. Psychological Bulletin, 125, 276-302. https://doi.org/10.1037/0033-2909.125.2.276

DiMino, J., \& Blau, G. (2012). The relationship between wait time after triage and show rate for intake in a non-urgent student population. Journal of College Student Psychotherapy, 26(3), 241-247. https://doi.org/10.1080/87568225.2012.685857

Draper, M. R., Jennings, J., Baron, A., Erdur, O., \& Shankar, L. (2002). Time-limited counseling outcome in a nationwide college counseling center sample. Journal of College Counseling, 5(1), 26-38. https://doi.org/10.1002/j.2161-1882.2002.tb00204.x

Eisenberg, D., Golberstein, E., \& Hunt, J. (2009). Mental health and academic success in college. The B.E. Journal of Economic Analysis \& Policy, 9(1), 1-37. https://doi.org/10.2202/1935-1682.2191

Fan, W., \& Yan, Z. (2010). Factors affecting response rates of the web survey: A systematic review. Computers in Human Behavior, 26(2), 132-139. https://doi.org/10.1016/j.chb.2009.10.015

Gallagher, R. P. (2014). National Survey of Counseling Center Directors. Retrieved December 28, 2016, from http://www.iacsinc.org/

Ghetie, D. (2007). The debate over time-limited treatment in college counseling centers. Journal of College Student Psychotherapy, 22(1), 41-61. https://doi.org/10.1300/J035v22n01_04

Green, J. L., Lowry, J. L., \& Kopta, M. (2003). College students versus college counseling center clients. Journal of College Student Psychotherapy, 17(4), 25-37. https://doi.org/10.1300/J035v17n04_05

Greenberger, E., Chen, C., Dmitrieva, J., \& Farruggia, S. (2003). Item-wording and the dimensionality of the Rosenberg Self-Esteem scale: Do they matter? Personality and Individual Differences, 35, 1241-1254. https://doi.org/10.1016/S0191-8869(02)00331-8

Hu, Y., Stewart-Brown, S., Twigg, L., \& Weich, S. (1997). Can the 12-item General Health Questionnaire be used to measure positive mental health? Psychological Medicine, 37(7), 1005-1013. https://doi.org/10.1017/S0033291707009993

Hunt, J. B., Watkins, D., \& Eisenberg, D. (2012). How do college campuses make decisions about allocating resources for student mental health? Findings from key participant interviews. Journal of College Student Development, 53(6), 850-856. https://doi.org/10.1353/csd.2012.0083

Kessler, R. C., Berglund, P., Demler, O., Jin, R., Merikangas, K. R., \& Walters, E. E. (2005). Lifetime prevalence and age-of-onset distributions of DSM-IV disorders in the National Comorbidity Survey Replication. Archives of General Psychiatry, 62(6), 593-602. https://doi.org/10.1001/archpsyc.62.6.593 
Kitzrow, M. A. (2009). The mental health needs of today's college students: Challenges and recommendations. NASPA Journal, 46(4), 646-660. https://doi.org/10.2202/1949-6605.5037

Kopta, S., Petrik, M., Saunders, S., Mond, M., Hirsch, G., Kadison, R., \& Raymond, D. (2014). The utility of an efficient outcomes assessment system at university counseling centers. Journal of College Student Psychotherapy, 28, 97-116. https://doi.org/10.1080/87568225.2014.883876

Kress, V. E., Newgent, R. A., Whitlock, J., \& Mease, L. (2015). Spirituality/religiosity, life satisfaction, and life meaning as protective factors for nonsuicidal self-injury in college students. Journal of College Counseling, 18(2), 160-174. https://doi.org/10.1002/jocc.12012

Lane, J. A. (2016). Attachment, well-being, and college senior concerns about the transition out of college. Journal of College Counseling, 19(3), 231-245. https://doi.org/10.1002/jocc.12046

Lucas, M. (2012). Counseling on campus: Client persistence and progress. Journal of College Student Psychotherapy, 26, 227-240. https://doi.org/10.1080/87568225.2012.685856

Mahon, M., Laux, J., McGuire Wise, S., Ritchie, M., Piazza, N., \& Tiamiyu, M. (2015). Brief therapy at a university counseling center: Working alliance, readiness to change, and symptom severity. Journal of College Counseling, 18, 223-243. https://doi.org/10.1002/jocc.12017

Nam, S., Chu, H., Lee, M., Lee, J., Kim, N., \& Lee, S. (2010). A meta-analysis of gender differences in attitudes towards seeking professional psychological help. Journal of American College Health, 59, 110-116. https://doi.org/10.1080/07448481.2010.483714

Pavot, W., \& Diener, E. (1993). A review of the Satisfaction with Life scale. Psychological Assessment, 5, 164-172. https://doi.org/10.1037/1040-3590.5.2.164

Rickes, P. (2009). Make way for Millenials!: How today's college students are shaping higher education space. Planning for Higher Education, 37(2), 7-17.

Rosenbaum, P. J., \& Liebert, H. (2015). Reframing the conversation on college student mental health. Journal of College Student Psychotherapy, 29(3), 179-196. https://doi.org/10.1080/87568225.2015.1045780

Rosenberg, M. (1965). Society and the adolescent self-image. Princeton, NJ: Princeton University Press. https://doi.org/10.1515/9781400876136

Roth, P. (1994). Missing data: A conceptual review for applied psychologists. Personnel Psychology, 47(3), 537-560. https://doi.org/10.1111/j.1744-6570.1994.tb01736.x

Schreiner, L., \& Nelson, D. (2013). The contribution of student satisfaction to persistence. Journal of College Student Retention, 15(1), 73-111. https://doi.org/10.2190/CS.15.1.f

Seligman, M. E. (1995). The effectiveness of psychotherapy: The Consumer Reports study. American Psychologist, 50(12), 965-974. https://doi.org/10.1037/0003-066X.50.12.965

Sparks, W., Daniels, J., \& Johnson, E. (2003). Relationship of referral source, race and wait time on pre-intake attrition. Professional Psychology: Research and Practice, 34(5), 514-518. https://doi.org/10.1037/0735-7028.34.5.514

Stevens, J. (1996). Applied Multivariate Statistics for the Social Sciences (3rd ed.). Mahwah, NJ: Erlbaum.

Surette, T., \& Shier, M. (2017). A common factors approach to supporting university students experiencing psychological distress. Journal of College Student Psychotherapy, 31(2), 112-131. https://doi.org/10.1080/87568225.2016.1248233

Webb, R., \& Widseth, J. (1988). Facilitating students' going into and stepping back from their inner worlds: Psychotherapy and the college student. Journal of College Student Psychotherapy, 3(1), 5-15. https://doi.org/10.1300/J035v03n01_02

\section{Copyrights}

Copyright for this article is retained by the author(s), with first publication rights granted to the journal.

This is an open-access article distributed under the terms and conditions of the Creative Commons Attribution license (http://creativecommons.org/licenses/by/4.0/). 